\title{
Interplay between sugar and hormone signaling pathways modulate floral signal transduction
}

\author{
lanis G. Matsoukas ${ }^{1,2 *}$ \\ 1 Institute for Renewable Energy and Environmental Technologies, University of Bolton, Bolton, UK \\ 2 Systems and Synthetic Biology, Institute for Materials Research and Innovation, University of Bolton, Bolton, UK
}

\section{Edited by:}

Christian Jung, Christian Albrechts

University of Kiel, Germany

\section{Reviewed by:}

Christina Kuehn, Humboldt

University, Germany

Li Yang, University of North Carolina

Chapel Hill, USA

Christian Jung, Christian Albrechts

University of Kiel, Germany

\section{*Correspondence:}

lanis G. Matsoukas, Institute for Renewable Energy and

Environmental Technologies,

Institute for Materials Research and

Innovation, University of Bolton,

Deane Road, Bolton BL3 5AB, UK

e-mail:i.matsoukas@bolton.ac.uk

\section{NOMENCLATURE}

The following nomenclature will be used in this article:

- Names of genes are written in italicized upper-case letters, e.g., $A B / 4$.

- Names of proteins are written in non-italicized upper-case letters, e.g., ABI4.

- Names of mutants are written in italicized lower-case letters, e.g., abi4.

The juvenile-to-adult and vegetative-to-reproductive phase transitions are major determinants of plant reproductive success and adaptation to the local environment. Understanding the intricate molecular genetic and physiological machinery by which environment regulates juvenility and floral signal transduction has significant scientific and economic implications. Sugars are recognized as important regulatory molecules that regulate cellular activity at multiple levels, from transcription and translation to protein stability and activity. Molecular genetic and physiological approaches have demonstrated different aspects of carbohydrate involvement and its interactions with other signal transduction pathways in regulation of the juvenile-to-adult and vegetative-to-reproductive phase transitions. Sugars regulate juvenility and floral signal transduction through their function as energy sources, osmotic regulators and signaling molecules. Interestingly, sugar signaling has been shown to involve extensive connections with phytohormone signaling. This includes interactions with phytohormones that are also important for the orchestration of developmental phase transitions, including gibberellins, abscisic acid, ethylene, and brassinosteroids. This article highlights the potential roles of sugar-hormone interactions in regulation of floral signal transduction, with particular emphasis on Arabidopsis thaliana mutant phenotypes, and suggests possible directions for future research.

Keywords: Arabidopsis thaliana, florigenic and antiflorigenic signaling, juvenile-to-adult phase transition, juvenility, signal transduction, sugar-hormone interactions, vegetative-to-reproductive phase transition

\section{INTRODUCTION}

The greatest advances in our understanding of the genetic regulation of developmental transitions have derived from studying the vegetative-to-reproductive phase transition in several dicot and monocot species. This has led to the elucidation of multiple environmental and endogenous pathways that promote, enable and repress floral induction (reviewed in Matsoukas et al., 2012). The photoperiodic (Kardailsky et al., 1999; Kobayashi et al., 1999) and vernalization (Schmitz et al., 2008) pathways regulate time to flowering in response to environmental signals such as daylength, light and temperature, whereas the autonomous (Jeong et al., 2009), aging (Yang et al., 2013; Yu et al., 2013) and gibberellin (GA)-dependent (Porri et al., 2012) pathways monitor endogenous indicators of the plant's age and physiological status. In addition, other factors and less characterized pathways also play a role in regulation of floral signal transduction. These include ethylene (Achard et al., 2006), brassinosteroids (BRs; Domagalska et al., 2010), salicylic acid (Jin et al., 2008) and cytokinins (D'aloia et al., 2011).

The photoperiodic pathway is probably the most conserved of the floral induction pathways. It is known for its promotive effect by relaying light and photoperiodic timing signals to floral induction (reviewed in Matsoukas et al., 2012). This pathway involves genes such as PHYTOCHROMES (PHYs; Sharrock and Quail, 1989; Clack et al., 1994) and CRYPTOCHROMES (CRYs; Ahmad and Cashmore, 1993; Guo et al., 1998; Kleine et al., 2003), which are involved in the regulation of light signal inputs. Other genes such as GIGANTEA (GI; Fowler et al., 1999), CIRCADIAN CLOCK ASSOCIATED1 (CCA1; Wang et al., 1997), and LATE ELONGATED HYPOCOTYL (LHY; Schaffer et al., 1998) are components of the circadian clock, whereas CONSTANS (CO), FLOWERING LOCUS T (FT; Kardailsky et al., 1999; Kobayashi et al., 1999), TWIN SISTER OF FT (TSF; Yamaguchi et al., 2005), and FLOWERING LOCUS D (FD; 
Abe et al., 2005) encode proteins that specifically regulate floral induction. The actions of all pathways ultimately converge to control the expression of so-called floral pathway integrators (FPIs), which include FT (Corbesier et al., 2007), TSF (Yamaguchi et al., 2005), SUPPRESSOR OF CONSTANS1 (SOC1; Yoo et al., 2005), and AGAMOUS-LIKE24 (AGL24; Lee et al., 2008; Liu et al., 2008). These act on floral meristem identity (FMI) genes LEAFY (LFY; Lee et al., 2008), FRUITFUL (FUL; Melzer et al., 2008), and APETALA1 (AP1; Wigge et al., 2005; Yamaguchi et al., 2005), which result in floral initiation. On the other hand, pathways that enable floral induction regulate the expression of floral repressors or translocatable florigen antagonists, known as antiflorigens (reviewed in Matsoukas et al., 2012). The pathways that regulate the floral repressor FLOWERING LOCUS $C$ (FLC) are the best-characterized (reviewed in Michaels, 2009).

The vegetative-to-reproductive phase transition is preceded by the juvenile-to-adult phase transition within the vegetative phase (reviewed in Poethig, 1990, 2013; Matsoukas et al., 2013; Matsoukas, 2014). During the juvenile phase plants are incapable of initiating reproductive development and are insensitive to environmental stimuli such as photoperiod and vernalization, which induce flowering in adult plants (Matsoukas et al., 2013; Matsoukas, 2014; Sgamma et al., 2014). The juvenileto-adult phase transition is accompanied by a decrease in microRNA156 (miR156A/miR156C) abundance and a concomitant increase in abundance of miR172, as well as the SQUAMOSA PROMOTER BINDING PROTEIN-LIKE (SPL3/4/5) transcription factors (TFs; Wang et al., 2009; Wu et al., 2009; Jung et al., 2011, 2012; Kim et al., 2012). Expression of miR172 activates $F T$ transcription in leaves through repression of AP2-like transcripts SCHLAFMÜTZE (SMZ), SCHNARCHZAPFEN (SNZ), and TARGET OF EAT 1-3 (TOE1-3; Jung et al., 2007, 2011; Mathieu et al., 2009), whereas the increase in SPLs at the shoot apical meristem (SAM), leads to the transcription of FMI genes (Schwab et al., 2005; Schwarz et al., 2008; Wang et al., 2009; Yamaguchi et al., 2009). Therefore, from a molecular perspective juvenility can be defined as the period during which the abundance of antiflorigenic signals such as miR156/miR157 is sufficiently high to repress the transcription of FT and SPL genes (Matsoukas, 2014).

Carbohydrates serve diverse functions in plants ranging from energy sources, osmotic regulators, storage molecules, and structural components to intermediates for the synthesis of other organic molecules (reviewed in Rolland et al., 2006; Smeekens et al., 2010; Eveland and Jackson, 2012). Carbohydrates also act as signaling molecules (Moore et al., 2003) and by their interaction with mineral networks (Zakhleniuk et al., 2001; Lloyd and Zakhleniuk, 2004) affect the juvenile-to-adult and vegetative-to-reproductive phase transitions (Matsoukas et al., 2013). Interestingly, sugar signaling has been shown to involve extensive interaction with hormone signaling (Zhou et al., 1998; Arenas-Huertero et al., 2000; Moore et al., 2003). This includes interactions with hormones that are also important for the regulation of juvenile-to-adult and vegetative-to-reproductive phase transitions, including GAs (Yuan and Wysocka-Diller, 2006), abscisic acid (ABA; Arenas-Huertero et al., 2000; Laby et al., 2000), ethylene (Zhou et al., 1998), and BRs (Goetz et al., 2000;
Schluter et al., 2002). Several molecular mechanisms that mediate sugar responses have been identified in plants (reviewed in Rolland et al., 2006; Smeekens et al., 2010). The best examples involve hexokinase (HXK; Moore et al., 2003), trehalose-6phosphate (Tre6P; Van Dijken et al., 2004) and the sucrose nonfermenting 1-related protein kinase1 (SnRK1; Baena-Gonzalez et al., 2007) complex. SnRK1 has a role when sugars are in extremely limited supply, whereas HXK and Tre6P play a role in the presence of excess sugar.

The panoptic themes of floral signal transduction, sugar sensing and signaling, and hormonal regulation of growth and development have attracted much attention, and many comprehensive review articles have been published (Rolland et al., 2006; Amasino, 2010; Smeekens et al., 2010; Depuydt and Hardtke, 2011; Huijser and Schmid, 2011; Andres and Coupland, 2012). This article, however, focuses specifically on sugar-hormone interactions and their involvement in regulation of floral signal transduction, with particular emphasis on Arabidopsis thaliana mutant phenotypes. The review is divided into two sections: the first provides several pieces of evidence on the interactions between sugars and different hormones in floral induction; whereas the second describes potential mechanisms that might be involved in regulation of floral signal transduction, in response to sugar-hormone interplay.

\section{SUGAR/HORMONE INTERACTIONS AND FLORAL SIGNAL TRANSDUCTION \\ THE SUGAR AND GIBBERELLIN SIGNALING CROSSTALK}

GAs are a group of molecules with a tetracyclic diterpenoid structure that function as plant growth regulators influencing a range of developmental processes. Several Arabidopsis mutants in the GA signal transduction and GA biosynthesis pathway have been isolated (Table 1; Peng and Harberd, 1993; Peng et al., 1997; Hedden and Phillips, 2000). Null mutations in the early steps of GA biosynthesis (e.g., gal-3) do not flower in short days (SDs), whereas weak mutants (e.g., ga1-6; Koornneef and Van Der Veen, 1980), or GA signal transduction mutants [e.g., gibberellic acid insensitive (gai)], flower later than wild type (WT; Peng and Harberd, 1993). In contrast, mutants with increased GA signaling such as rga like2 (rgl2; Cheng et al., 2004; Yu et al., 2004) and spindly (spy; Jacobsen and Olszewski, 1993) have an early flowering phenotype. Evidence has been provided that both RGL2 and SPY might be involved in carbohydrate regulation of floral initiation, as mutation in both loci confers insensitivity to inhibiting glucose concentrations (Yuan and Wysocka-Diller, 2006). SPY, an O-linked $B-\mathrm{N}$-acetylglucosamine transferase was shown to interact with the GI in yeast (Tseng et al., 2004). Mutants impaired in GI have a late flowering and starch-excess phenotype (Eimert et al., 1995). The interaction between SPY and GI suggests that functions of these proteins might be related, and that SPY might be a pleiotropic circadian clock regulator (Tseng et al., 2004; Penfield and Hall, 2009). In addition, the early flowering phenotype of the glucose insensitive spy may be via FT, as spy 4 suppresses the reduction of $C O$ and FT mRNA in gi2 genotypes (Tseng et al., 2004). This indicates that SPY functions in the photoperiod pathway upstream of $C O$ and FT, involving glucose and GA metabolism-related events. Interestingly, it 


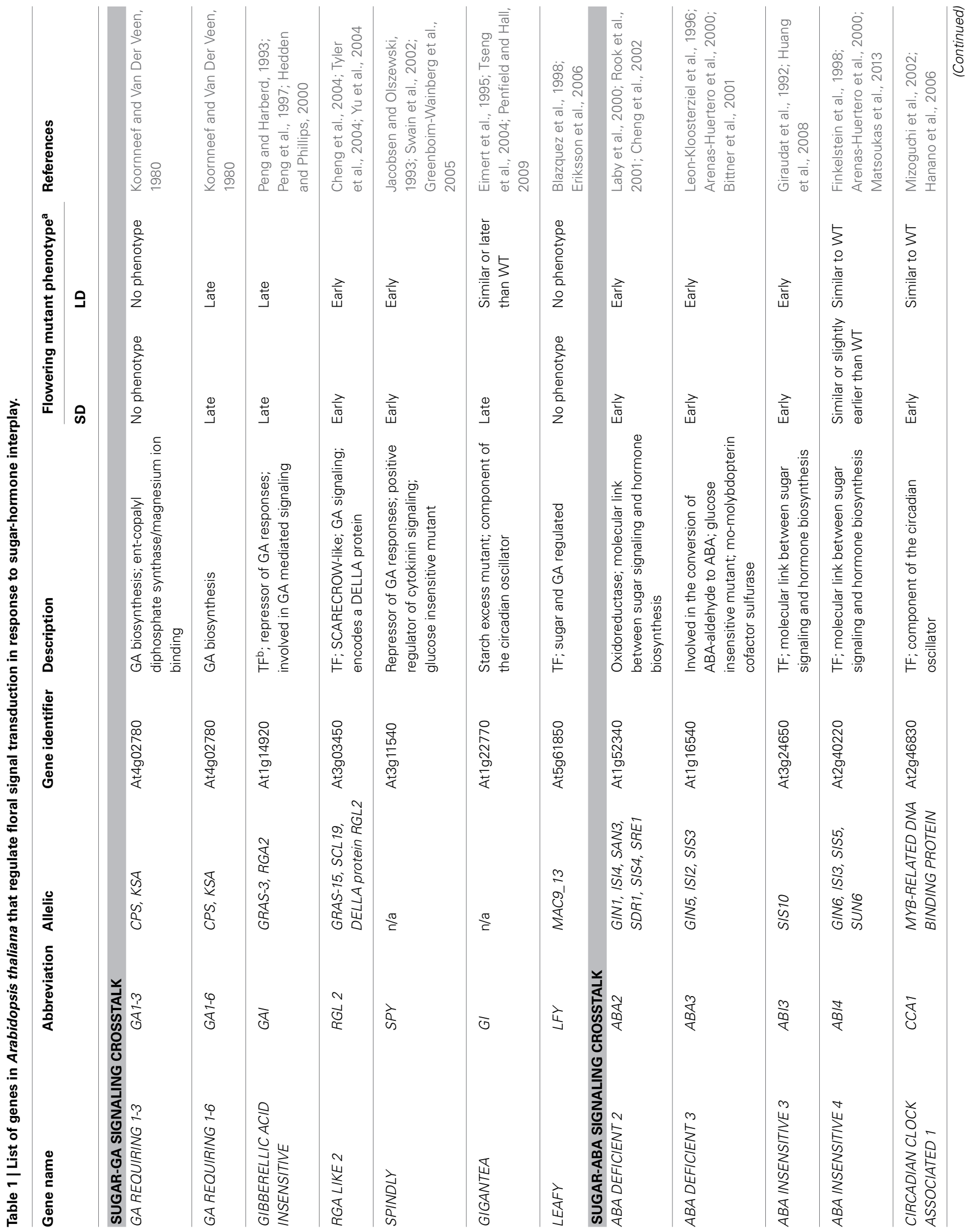




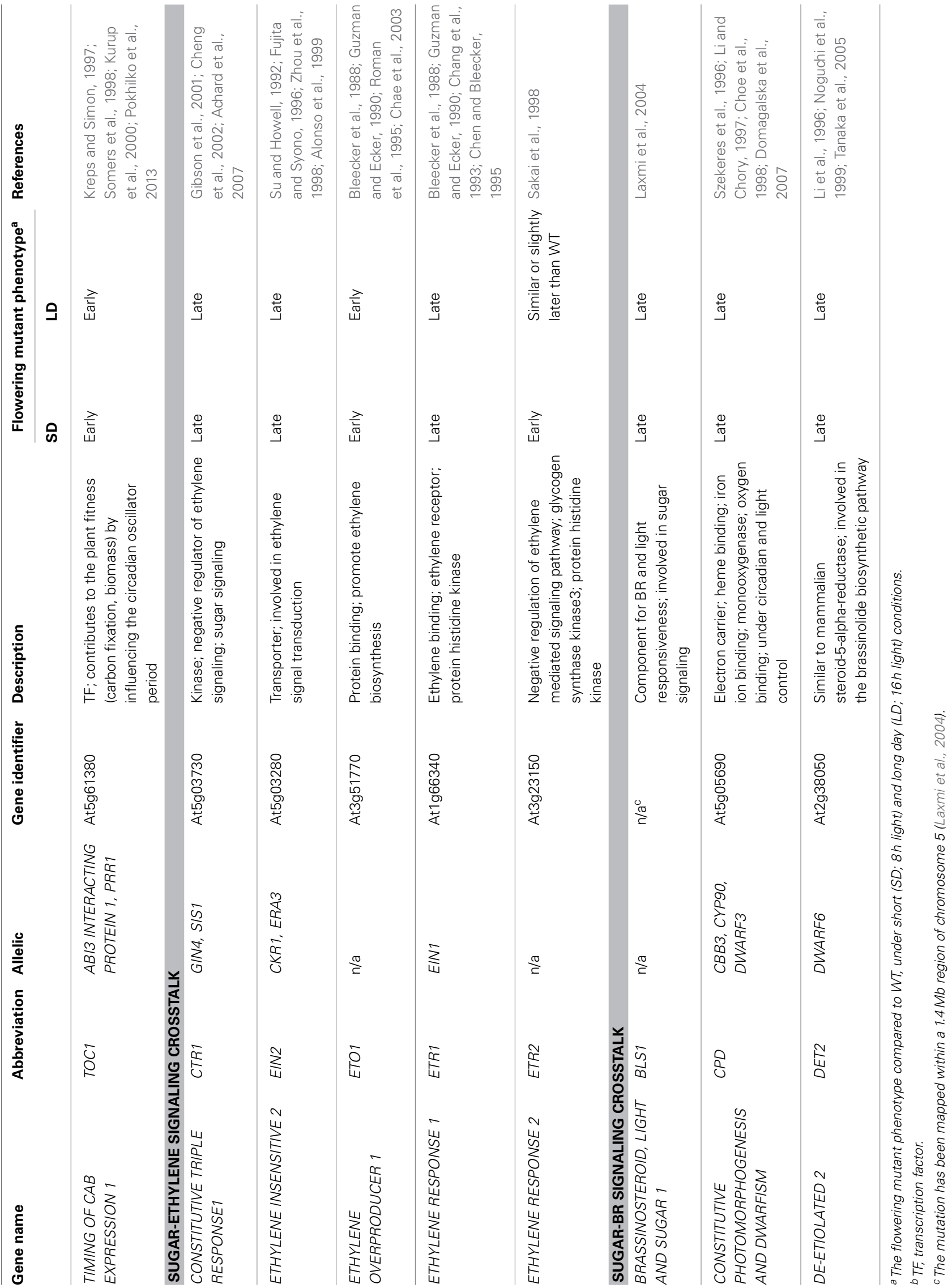


has been suggested that SPY4 may play a central role in the regulation of $\mathrm{GA} /$ cytokinin crosstalk during plant development (Greenboim-Wainberg et al., 2005).

Lines of evidence have demonstrated that there is a synergistic interaction between GAs and sucrose in the activation of LFY transcription (Blazquez et al., 1998; Eriksson et al., 2006). These pieces of evidence suggest a further link between GAs with sugar metabolism-related events and floral signal transduction. The effects of GA-sugar interplay on regulation of floral induction might be transduced by the GIBBERELLIN INSENSITIVE DWARF1 (GID1), which act upstream of the DELLA (Feng et al., 2008; Harberd et al., 2009), and PHYTOCHROME-INTERACTING FACTOR (PIF; De Lucas et al., 2008; Nozue et al., 2011; Stewart et al., 2011) family of bHLH factors.

\section{THE SUGAR-ABA SIGNALING CROSSTALK}

ABA is regarded as a general inhibitor of floral induction. This is indicated in Arabidopsis where mutants deficient (e.g., aba2, $a b a 3$ ) in or insensitive [e.g., aba insensitive4 (abi4)] to ABA are early flowering (Table 1; Martinez-Zapater et al., 1994). On the other hand, mutants with high ABA levels [e.g., no hydrotropic response $(n h r 1)$ ] flower late or even later than WT under noninductive SDs (Quiroz-Figueroa et al., 2010). However, many mutations affecting sugar signaling are allelic with components of the ABA synthesis or ABA transduction pathways. It has been shown that aba2, aba3, and abi4 mutants are allelic to sugarinsensitive mutants glucose insensitive1 (gin1)/impaired sucrose induction4 (isi4)/sugar insensitive1 (sis1; Laby et al., 2000; Rook et al., 2001), gin5/isi2/sis3 (Arenas-Huertero et al., 2000) and gin6/isi3/sis5/sun6 (Arenas-Huertero et al., 2000), respectively. In addition, ABA accumulation and transcript levels of several ABA biosynthetic genes are significantly increased by glucose (Cheng et al., 2002). These lines of evidence indicate that signaling pathways mediated by ABA and sugars may interact to regulate juvenility and floral signal transduction (Matsoukas et al., 2013).

The downstream effects of the sugar-ABA interaction might be mediated via the circadian clock. Photoperiodic induction requires the circadian clock to measure the duration of the day or night (reviewed in Harmer, 2009; Imaizumi, 2010). The clock modulates the expression of $C O$, the precursor of FT that accelerates flowering in response to several pathways (reviewed in Turck et al., 2008). It has been shown that glucose has a marked effect on the entrainment and maintenance of robust circadian rhythms (Dalchau et al., 2011; Haydon et al., 2013). In addition, circadian periodicity is also regulated by ABA via an unclear mechanism. This might be through ABI3 (allelic to sis10; Huang et al., 2008) by binding to the clock component TIMING OF CAB EXPRESSION1 (TOC1; also called ABI3 Interacting Protein 1; Kurup et al., 2000; Pokhilko et al., 2013), and/or regulation of CCA1 mRNA transcription levels by ABA (Hanano et al., 2006). Thus, gating of circadian clock sensitivity by the $\mathrm{ABA}$ and sugar crosstalk may constitute a regulatory module that coordinates the circadian clock with additional endogenous and environmental signals to regulate juvenility and floral signal transduction.

\section{THE SUGAR-ETHYLENE SIGNALING CROSSTALK}

Ethylene is another example of a phytohormone that regulates juvenility (Beyer and Morgan, 1971) and floral induction (Bleecker et al., 1988; Guzman and Ecker, 1990). Arabidopsis mutants impaired in ethylene signaling [e.g., ethylene insensitive2 (ein2), ein3-1] or perception [e.g., ethylene response1 (etr1-1)], flower late in inductive LDs (Table 1). This late flowering phenotype is significantly enhanced under non-inductive SDs. Mutants, which over-produce ethylene [e.g., ethylene overproducer1 (eto1), eto2-1] flower at the same time or slightly earlier than WT under LDs, but dramatically later in SDs (Bleecker et al., 1988; Guzman and Ecker, 1990; Chen and Bleecker, 1995; Achard et al., 2007). Ample evidence has shown that ethylene can influence plant sensitivity to sugars. Ethylene-insensitive plants are more sensitive to endogenous glucose, whereas application of an ethylene precursor decreases glucose sensitivity (Zhou et al., 1998; Leon and Sheen, 2003). However, this interaction may also function in an antithetical way as several ethylene biosynthetic and signal transduction genes are repressed by glucose (Yanagisawa et al., 2003; Price et al., 2004).

Ethylene sensing and signaling pathways are also tightly interconnected with those for sugar and ABA (reviewed in Gazzarrini and Mccourt, 2001; Leon and Sheen, 2003). Lines of evidence have shown that this crosstalk modulates the vegetative-toreproductive phase transition. This is suggested by the glucose hypersensitive phenotype displayed by the late flowering mutants ein2 [allelic to enhanced response to aba3 (era3)], ein3 and etr1 (Chang et al., 1993; Zhou et al., 1998; Alonso et al., 1999; Cheng et al., 2002; Yanagisawa et al., 2003). Activation of the ethylene response [either in the presence of exogenous ethylene or by means of the eto1 or constitutive triple response1 (ctr1) mutations] attenuates the glucose effects (Zhou et al., 1998; Gibson et al., 2001). Further support for the sugar-ethylene crosstalk involvement on flowering time is derived by the epistatic analysis of the etr1 gin1 (aba2) and ein2 gin1 (aba2) double mutants in the elucidated role of GIN1 (ABA2) in the ethylene signal transduction cascade. The etr1 gin1 (aba2) and ein 2 gin1 (aba2) double mutants flower earlier than etr1 and ein 2 single mutants, respectively (Cheng et al., 2002). The early flowering and glucose resistance phenotypes of the double mutants etr1 gin1 (aba2) and ein2 gin1 (aba2) under LDs, may suggest that ethylene affects glucose signaling, partially, through ABA to regulate floral induction (Zhou et al., 1998; Cheng et al., 2002; Ghassemian et al., 2006). Overexpression of ETHYLENE RESPONSE2 (ETR2; Sakai et al., 1998) receptor in Oryza sativa reduced ethylene sensitivity and delayed floral induction (Wuriyanghan et al., 2009). Conversely, disruption of ETR2 by T-DNA or with RNA interference (RNAi) conferred enhanced ethylene sensitivity and early flowering. Moreover, links of the ethylene signaling with starch accumulation responses and activation of sugar transporter genes have also been observed. ETR2 promoted starch accumulation, whereas a monosaccharide transporter gene was suppressed in the ETR2 over-expression lines (Wuriyanghan et al., 2009). Interestingly, when expression of ETR2 was reduced in the OSetr2 T-DNA and RNAi lines, starch failed to accumulate, whereas sugar translocation was enhanced (Wuriyanghan et al., 2009). 
Ethylene has dramatic effects on flowering time of mutants involved in activation of the ethylene response under SD conditions (Achard et al., 2007). CONSTITUTIVE TRIPLE RESPONSE1 (CTR1) is a major negative regulator of ethylene signaling that is allelic to GIN4 (Cheng et al., 2002) and SIS1 (Gibson et al., 2001). Loss-of-function ctr1 mutations result in the constitutive activation of the ethylene response pathway, which indicates that the encoded protein acts as a negative regulator of ethylene signaling (Kieber et al., 1993). Under LDs ctr1 has a flowering phenotype similar to WT. In antithesis with the other glucose insensitive genotypes, ctr1 plants flower dramatically later than WT in SDs. This could be due to impaired involvement of GA pathway, which systematize floral initiation in SDs. Interestingly, evidence has been provided that ethylene dramatically prolongs time to flowering in ctr1 under SDs by repressing the up-regulation of $L F Y$ and $S O C 1$ transcript levels via a DELLA-dependent mechanism, and decreasing the levels of the endogenous bioactive GAs (Achard et al., 2007).

\section{THE SUGAR-BRASSINOSTEROIDS SIGNALING CROSSTALK}

BRs are steroid hormones known to control various skotomorphogenic (Chory et al., 1991) and photomorphogenic (Li et al., 1996) aspects of development. Genetic and physiological analyses have revealed the critical role of BRs in floral induction (Table 1), establishing a new floral signal transduction pathway. The promotive role of BRs on floral induction is exerted by the late flowering phenotype of BR-deficient mutants brassinosteroid-insensitive1 (brs1; Clouse et al., 1996; Li and Chory, 1997), brassinosteroidinsensitive2 (bin2; Li et al., 2001), deetiolated2 (det2; Chory et al., 1991), constitutive photomorphogenesis and dwarfism (cpd; Szekeres et al., 1996; Domagalska et al., 2007) and brassinosteroid, light and sugar1 (bls1; Laxmi et al., 2004). Conversely, mutations impaired in metabolizing BRs to their inactive forms, phyB-activation-tagged suppressor1 (bas1; Neff et al., 1999) and suppressor of phyB-4 7 (sob7; Turk et al., 2005) flower early (Turk et al., 2005). It has been reported that the response to exogenously applied BRs differs depending on the light quality and quantity (Neff et al., 1999), suggesting a potential interaction with sugars via light-mediated pathways (Goetz et al., 2000; Schluter et al., 2002). In addition, it has been demonstrated that BR responses are related to hormones such as GA (Gallego-Bartolome et al., 2012), ABA (Domagalska et al., 2010), and ethylene (Turk et al., 2005), which participate in sugar signaling. Furthermore, the sugar hypersensitive phenotype of the late flowering $b l s 1$ can be repressed by exogenous BRs (Laxmi et al., 2004). Moreover, the late flowering mutant $\operatorname{det} 2$, as other constitutively photomorphogenic mutants have been found to have an altered response to applied sugars (reviewed in Chory et al., 1996; Laxmi et al., 2004, and references therein). Collectively, these data indicate interplay between BRs and sugars in regulation of floral signal transduction. The downstream effects of this crosstalk might be mediated through BRASSINAZOLE RESISTANT1 (BZR1) and BZR2, as well as additional interacting TFs. Both BZR1 and BZR2 interact with PIF (Oh et al., 2012) and the GA signaling DELLA proteins (Oh et al., 2012). In addition, the BR-sugar interaction may also be indirectly involved in modulation of juvenility and floral signal transduction by influencing the photoperiodic pathway via the circadian clock, as BR application shortens circadian rhythms (Hanano et al., 2006).

\section{HOW DOES THE CROSSTALK BETWEEN SUGARS AND HORMONES REGULATE THE FLORAL SIGNAL TRANSDUCTION}

It is proposed that the effects of the sugar-hormone interplay might be mediated by hormones that enable tissues to respond to sugars, and/or hormone and sugar signaling, although essentially separate, could converge and crosstalk through specific regulatory complexes (Figure 1). One regulatory mechanism might be through metabolic enzymes, which also function as active members of transcriptional or posttranscriptional regulatory complexes (Cho et al., 2006). This cross-functionalization could be involved in mechanisms that modulate juvenility and floral signal transduction, by allowing interplay between different sugar and hormone response pathways or receptors.

\section{THE HXK1-miR156 REGULATORY MODULE}

Sugar signals can be generated either by carbohydrate concentration and relative ratios to other metabolites, such as hormones (Arenas-Huertero et al., 2000) and carbon-nitrogen ratio (Corbesier et al., 2002; Rolland et al., 2006), or by flux through sugar-specific transporters (Lalonde et al., 1999) and/or sensors (Moore et al., 2003). Sugar sensors perceive the presence of different sugars and initiate downstream signaling events. Glucose (Moore et al., 2003), fructose (Cho and Yoo, 2011; Li et al., 2011), sucrose (Seo et al., 2011), Tre6P (Van Dijken et al., 2004), and maltose (Niittyla et al., 2004; Stettler et al., 2009) function as cellular signaling molecules in specific regulatory pathways, which modulate juvenility and floral signal transduction. Of these signaling molecules, glucose has been studied the most comprehensively in plants.

Glucose-mediated floral signal transduction is largely dependent on HXK, HXK-independent, and SnRK1 signaling pathways. One possibility is that HXK1 controls juvenility and floral signal transduction by regulating the expression of miR156 (Yang et al., 2013). In this scenario, HXK1 that is largely dependent on ABA biosynthesis and signaling components (Zhou et al., 1998; Arenas-Huertero et al., 2000) promotes miR156 expression under low sugar levels. Above a threshold concentration, the circadian fluctuations of glucose, one of the final outputs of starch degradation (Stitt and Zeeman, 2012) that is regulated by starch and Tre6P (Martins et al., 2013) promotes GA biosynthesis (Cheng et al., 2002; Yu et al., 2012; Paparelli et al., 2013) and blocks HXK1 activity, resulting in downregulation of miR156 expression (Yang et al., 2013; Yu et al., 2013). Interestingly, defoliation experiments (Yang et al., 2011, 2013; Yu et al., 2013) show that removing the two oldest leaves results in increased miR156 levels at the SAM and a prolonged juvenile phase length. The fact that glucose, fructose, sucrose and maltose, partially, reverse this effect (Wang et al., 2013; Yu et al., 2013), indicates that photosynthetically derived sugars are potential components of the signal transduction pathway that repress miR156 expression in leaf primordia.

It seems highly probable that the differential regulation of SnRK1 by ABA and GAs (Bradford et al., 2003), and the 


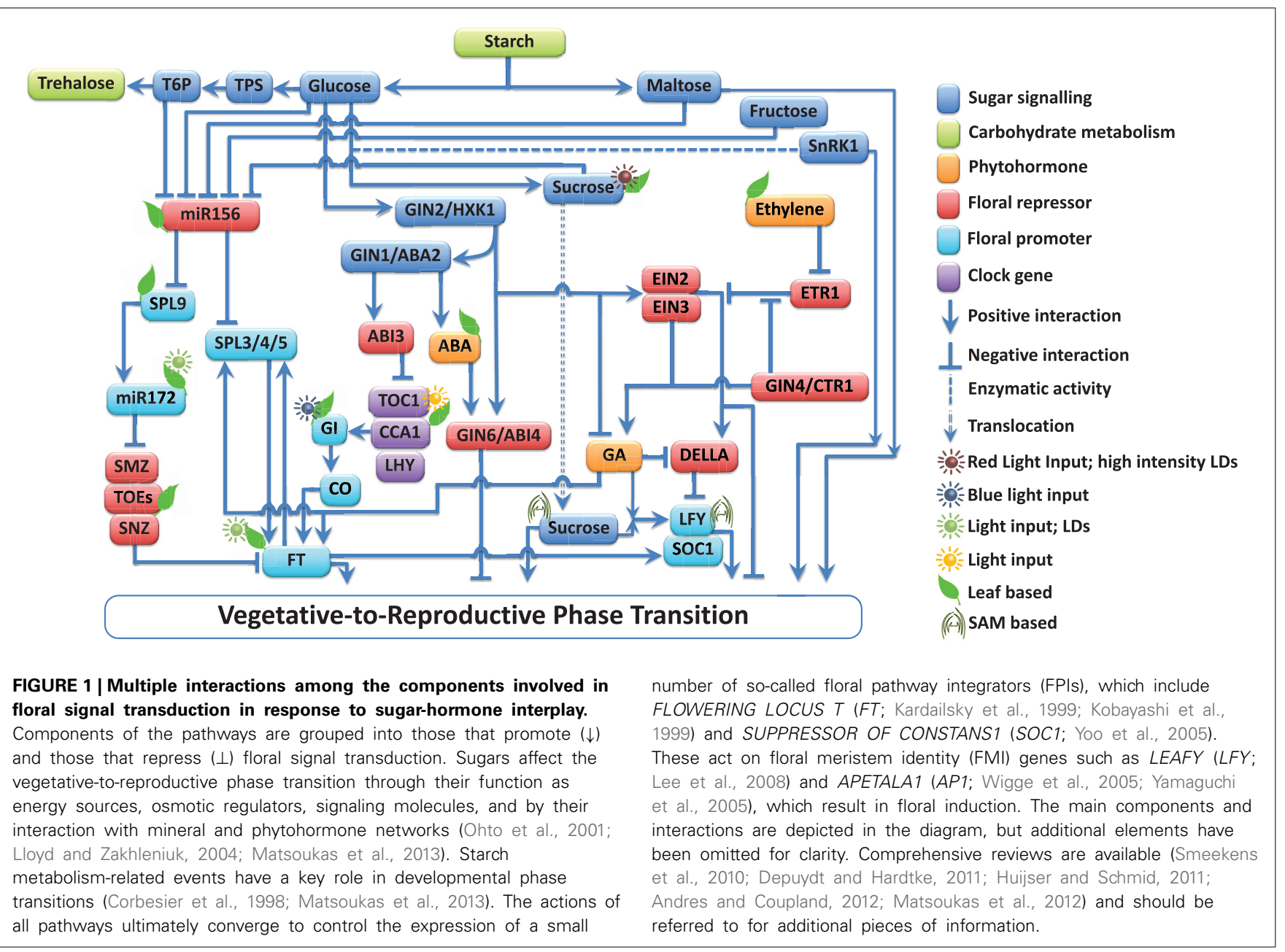

antagonism between $\mathrm{ABA}$ and $\mathrm{GA}$, which function in an opposite manner, to activate specific $c i s$-acting regulatory elements present in ABA- and GA-responsive promoters respectively (reviewed in Yamaguchi-Shinozaki and Shinozaki, 2005), may also be involved in this regulatory module (Achard et al., 2006; Yu et al., 2012; Wang et al., 2013).

\section{THE TRE6P-miR156 REGULATORY MODULE}

Tre6 $\mathrm{P}$ is a metabolite of emerging significance in plant developmental biology, with hormone-like metabolic activities (reviewed in Smeekens et al., 2010; Ponnu et al., 2011). It has been proposed that Tre6P signals the availability of sucrose (Lunn et al., 2006), and then through the SnRK1 regulatory system orchestrates changes in gene expression that enable sucrose to regulate juvenility and floral signal transduction. In Arabidopsis, Tre6 $\mathrm{P}$ is synthesized from glucose-6-phospate by TREHALOSE PHOSPHATE SYNTHASE 1 (TPS1; Van Dijken et al., 2004). Nonembryo-lethal weak alleles of tps1 exhibit late flowering (Van Dijken et al., 2004) and ABA hypersensitive phenotypes (Gomez et al., 2010). Interestingly, the Tre6P pathway controls the expression of SPL3, SPL4, and SPL5 at the SAM, partially via miR156, and partly independently of the miR156-dependent pathway via FT (Wahl et al., 2013). Several pieces of evidence suggest that
Tre6P inhibits SnRK1 when sucrose is above a threshold concentration (Polge and Thomas, 2007; Zhang et al., 2009). When the sucrose content decreases, with Tre6P decreasing as well, SnRK1 is released from repression, which leads to the induction of genes involved in photosynthesis-related events, so that more carbon is made available (Delatte et al., 2011). It has been shown that the Tre6P-SnRK1 module acts through a mechanism involving ABA (Gomez et al., 2010) and sugar metabolism (Van Dijken et al., 2004) to regulate several developmental events. The key link between sugars and ABA perception is exemplified by the $A B I$ genes (Eveland and Jackson, 2012; Wang et al., 2013). Interestingly, $A B I 4$ encodes an AP2 domain TF that is required for normal sugar responses during the early stages of development (Arenas-Huertero et al., 2000; Laby et al., 2000; Rook et al., 2001; Niu et al., 2002). Taken together, these data could provide another mechanistic link, at the molecular level, on how the ABAsugar interplay might be involved in regulation of juvenility and floral signal transduction.

\section{PERSPECTIVES}

Sugars serve diverse functions in plants ranging from energy sources, osmotic regulators, storage molecules, and structural components to intermediates for the synthesis of other organic 
molecules. Sugars also act as signaling molecules and by their interaction with mineral and hormonal networks affect several aspects of growth and development.

There has been a long-standing interest in the role played by sugars and hormones in regulation of the juvenile-to-adult and vegetative-to-reproductive phase transitions. It has been proposed that the effects of sugar-hormone interactions might be mediated by key hormones that enable tissues to respond to sugars, and/or hormone and sugar signaling could converge and crosstalk through specific regulatory complexes and/or metabolic enzymes. However, how sugar and hormone signals are integrated into genetic pathways that regulate the juvenile-to-adult and vegetative-to-reproductive phase transitions is still incompletely understood. Recent studies have shown that metabolic enzymes, ABA, GA and Tre6P may integrate into the miR156/SPL-signaling pathway. However, despite this progress, mechanistic questions remain. Future challenges include the further clarification of the antagonistic and agonistic interactions between the sugarand hormone-derived signals in a spatio-temporal manner at the molecular level, and their link to other known important transcriptional regulatory networks.

\section{ACKNOWLEDGMENTS}

The author would like to thank Professor Brian Thomas (University of Warwick, UK) and Dr Andrea Massiah (University of Warwick, UK) for valuable discussions, and the three independent reviewers for their comments on the manuscript. Ianis G. Matsoukas is supported by the Hellenic State Scholarships Foundation and University of Bolton (UK).

\section{REFERENCES}

Abe, M., Kobayashi, Y., Yamamoto, S., Daimon, Y., Yamaguchi, A., Ikeda, Y., et al. (2005). FD, a bZIP protein mediating signals from the floral pathway integrator FT at the shoot apex. Science 309, 1052-1056. doi: 10.1126/science. 1115983

Achard, P., Baghour, M., Chapple, A., Hedden, P., Van Der Straeten, D., Genschik, P., et al. (2007). The plant stress hormone ethylene controls floral transition via DELLA-dependent regulation ot floral meristem-identity genes. Proc. Natl. Acad. Sci. U.S.A. 104, 6484-6489. doi: 10.1073/pnas.0610717104

Achard, P., Cheng, H., De Grauwe, L., Decat, J., Schoutteten, H., Moritz, T., et al. (2006). Integration of plant responses to environmentally activated phytohormonal signals. Science 311, 91-94. doi: 10.1126/science.1118642

Ahmad, M., and Cashmore, A. R. (1993). HY4 gene of A. thaliana encodes a protein with characteristics of a blue-light photoreceptor. Nature 366, 162-166. doi: $10.1038 / 366162 \mathrm{a} 0$

Alonso, J. M., Hirayama, T., Roman, G., Nourizadeh, S., and Ecker, J. R. (1999). EIN2, a bifunctional transducer of ethylene and stress responses in Arabidopsis. Science 284, 2148-2152. doi: 10.1126/science.284.5423.2148

Amasino, R. (2010). Seasonal and developmental timing of flowering. Plant J. 61, 1001-1013. doi: 10.1111/j.1365-313X.2010.04148.x

Andres, F., and Coupland, G. (2012). The genetic basis of flowering responses to seasonal cues. Nat. Rev. Genet. 13, 627-639. doi: 10.1038/nrg3291

Arenas-Huertero, F., Arroyo, A., Zhou, L., Sheen, J., and Leon, P. (2000). Analysis of Arabidopsis glucose insensitive mutants, gin5 and gin6, reveals a central role of the plant hormone ABA in the regulation of plant vegetative development by sugar. Genes Dev. 14, 2085-2096. doi: 10.1101/gad.14.16.2085

Baena-Gonzalez, E., Rolland, F., Thevelein, J. M., and Sheen, J. (2007). A central integrator of transcription networks in plant stress and energy signalling. Nature 448, 938-942. doi: 10.1038/nature06069

Beyer, E. M., and Morgan, P. W. (1971). Abscission: the role of ethylene modification of auxin transport. Plant Physiol. 48, 208-212. doi: 10.1104/pp. 48.2.208
Bittner, F., Oreb, M., and Mendel, R. R. (2001). ABA3 is a molybdenum cofactor sulfurase required for activation of aldehyde oxidase and xanthine dehydrogenase in Arabidopsis thaliana. J. Biol. Chem. 276, 40381-40384. doi: 10.1074/jbc.C100472200

Blazquez, M. A., Green, R., Nilsson, O., Sussman, M. R., and Weigel, D. (1998). Gibberellins promote flowering of Arabidopsis by activating the LEAFY promoter. Plant Cell 10, 791-800. doi: 10.1105/tpc.10.5.791

Bleecker, A. B., Estelle, M. A., Somerville, C., and Kende, H. (1988). Insensitivity to ethylene conferred by a dominant mutation in Arabidopsis thaliana. Science 241, 1086-1089. doi: 10.1126/science.241.4869.1086

Bradford, K. J., Downie, A. B., Gee, O. H., Alvarado, V., Yang, H., and Dahal, P. (2003). Abscisic acid and gibberellin differentially regulate expression of genes of the SNF1-related kinase complex in tomato seeds. Plant Physiol. 132, 1560-1576. doi: 10.1104/pp.102.019141

Chae, H. S., Faure, F., and Kieber, J. J. (2003). The eto1, eto2, and eto3 mutations and cytokinin treatment increase ethylene biosynthesis in Arabidopsis by increasing the stability of ACS protein. Plant Cell 15, 545-559. doi: 10.1105/tpc.006882

Chang, C., Kwok, S. F., Bleecker, A. B., and Meyerowitz, E. M. (1993). Arabidopsis ethylene-response gene ETR1: similarity of product to two-component regulators. Science 262, 539-544. doi: 10.1126/science.8211181

Chen, Q. G., and Bleecker, A. B. (1995). Analysis of ethylene signal-transduction kinetics associated with seedling-growth response and chitinase induction in wild-type and mutant arabidopsis. Plant Physiol. 108, 597-607. doi: 10.1104/pp.108.2.597

Cheng, H., Qin, L., Lee, S., Fu, X., Richards, D. E., Cao, D., et al. (2004). Gibberellin regulates Arabidopsis floral development via suppression of DELLA protein function. Development 131, 1055-1064. doi: 10.1242/dev.00992

Cheng, W. H., Endo, A., Zhou, L., Penney, J., Chen, H. C., Arroyo, A., et al. (2002). A unique short-chain dehydrogenase/reductase in Arabidopsis glucose signaling and abscisic acid biosynthesis and functions. Plant Cell 14, 2723-2743. doi: 10.1105/tpc.006494

Cho, Y. H., and Yoo, S. D. (2011). Signaling role of fructose mediated by FINS1/FBP in Arabidopsis thaliana. PLoS Genet. 7:e1001263. doi: 10.1371/journal.pgen.1001263

Cho, Y. H., Yoo, S. D., and Sheen, J. (2006). Regulatory functions of nuclear hexokinase1 complex in glucose signaling. Cell 127, 579-589. doi: 10.1016/j.cell.2006.09.028

Choe, S., Dilkes, B. P., Fujioka, S., Takatsuto, S., Sakurai, A., and Feldmann, K. A. (1998). The DWF4 gene of Arabidopsis encodes a cytochrome P450 that mediates multiple 22alpha-hydroxylation steps in brassinosteroid biosynthesis. Plant Cell 10, 231-243.

Chory, J., Catterjee, M., Cook, R. K., Elich, T., Fankhauser, C., Li, J., et al. (1996). From seed germination to flowering, light controls plant development via the pigment phytochrome. Proc. Natl. Acad. Sci. U.S.A. 93, 12066-12071. doi: 10.1073/pnas.93.22.12066

Chory, J., Nagpal, P., and Peto, C. A. (1991). Phenotypic and genetic analysis of det2, a new mutant that affects light-regulated seedling development in Arabidopsis. Plant Cell 3, 445-459. doi: 10.1105/tpc.3.5.445

Clack, T., Mathews, S., and Sharrock, R. A. (1994). The phytochrome apoprotein family in Arabidopsis is encoded by five genes: the sequences and expression of PHYD and PHYE. Plant Mol. Biol. 25, 413-427. doi: 10.1007/BF00043870

Clouse, S. D., Langford, M., and Mcmorris, T. C. (1996). A brassinosteroidinsensitive mutant in Arabidopsis thaliana exhibits multiple defects in growth and development. Plant Physiol. 111, 671-678. doi: 10.1104/pp.111.3.671

Corbesier, L., Bernier, G., and Perilleux, C. (2002). C: N ratio increases in the phloem sap during floral transition of the long-day plants Sinapis alba and Arabidopsis thaliana. Plant Cell Physiol. 43, 684-688. doi: 10.1093/pcp/pcf071

Corbesier, L., Lejeune, P., and Bernier, G. (1998). The role of carbohydrates in the induction of flowering in Arabidopsis thaliana: comparison between the wild type and a starchless mutant. Planta 206, 131-137. doi: 10.1007/s004250050383

Corbesier, L., Vincent, C., Jang, S. H., Fornara, F., Fan, Q. Z., Searle, I., et al. (2007). FT protein movement contributes to long-distance signaling in floral induction of Arabidopsis. Science 316, 1030-1033. doi: 10.1126/science. 1141752

D’aloia, M., Bonhomme, D., Bouche, F., Tamseddak, K., Ormenese, S., Torti, S., et al. (2011). Cytokinin promotes flowering of Arabidopsis via transcriptional activation of the FT paralogue TSF. Plant J. 65, 972-979. doi: 10.1111/j.1365313X.2011.04482.x 
Dalchau, N., Baek, S. J., Briggs, H. M., Robertson, F. C., Dodd, A. N., Gardner, M. J., et al. (2011). The circadian oscillator gene GIGANTEA mediates a long-term response of the Arabidopsis thaliana circadian clock to sucrose. Proc. Natl. Acad. Sci. U.S.A. 108, 5104-5109. doi: 10.1073/pnas.1015452108

De Lucas, M., Daviere, J. M., Rodriguez-Falcon, M., Pontin, M., Iglesias-Pedraz, J. M., Lorrain, S., et al. (2008). A molecular framework for light and gibberellin control of cell elongation. Nature 451, 480-484. doi: 10.1038/nature06520

Delatte, T. L., Sedijani, P., Kondou, Y., Matsui, M., De Jong, G. J., Somsen, G. W., et al. (2011). Growth arrest by trehalose-6-phosphate: an astonishing case of primary metabolite control over growth by way of the SnRK1 signaling pathway. Plant Physiol. 157, 160-174. doi: 10.1104/pp.111.180422

Depuydt, S., and Hardtke, C. S. (2011). Hormone signalling crosstalk in plant growth regulation. Curr. Biol. 21, R365-R373. doi: 10.1016/j.cub.2011.03.013

Domagalska, M. A., Sarnowska, E., Nagy, F., and Davis, S. J. (2010). Genetic analyses of interactions among gibberellin, abscisic acid, and brassinosteroids in the control of flowering time in Arabidopsis thaliana. PLoS ONE 5:e14012. doi: 10.1371/journal.pone.0014012

Domagalska, M. A., Schomburg, F. M., Amasino, R. M., Vierstra, R. D., Nagy, F., and Davis, S. J. (2007). Attenuation of brassinosteroid signaling enhances FLC expression and delays flowering. Development 134, 2841-2850. doi: $10.1242 /$ dev.02866

Eimert, K., Wang, S. M., Lue, W. I., and Chen, J. (1995). Monogenic recessive mutations causing both late floral initiation and excess starch accumulation in Arabidopsis. Plant Cell 7, 1703-1712. doi: 10.1105/tpc.7.10.1703

Eriksson, S., Bohlenius, H., Moritz, T., and Nilsson, O. (2006). GA4 is the active gibberellin in the regulation of LEAFY transcription and Arabidopsis floral initiation. Plant Cell 18, 2172-2181. doi: 10.1105/tpc.106.042317

Eveland, A. L., and Jackson, D. P. (2012). Sugars, signalling, and plant development. J. Exp. Bot. 63, 3367-3377. doi: 10.1093/jxb/err379

Feng, S., Martinez, C., Gusmaroli, G., Wang, Y., Zhou, J., Wang, F., et al. (2008). Coordinated regulation of Arabidopsis thaliana development by light and gibberellins. Nature 451, 475-479. doi: 10.1038/nature06448

Finkelstein, R. R., Wang, M. L., Lynch, T. J., Rao, S., and Goodman, H. M. (1998). The Arabidopsis abscisic acid response locus ABI4 encodes an APETALA 2 domain protein. Plant Cell 10, 1043-1054.

Fowler, S., Lee, K., Onouchi, H., Samach, A., Richardson, K., Morris, B., et al. (1999). GIGANTEA: a circadian clock-controlled gene that regulates photoperiodic flowering in Arabidopsis and encodes a protein with several possible membrane-spanning domains. EMBO J. 18, 4679-4688. doi: 10.1093/emboj/18.17.4679

Fujita, H., and Syono, K. (1996). Genetic analysis of the effects of polar auxin transport inhibitors on root growth in Arabidopsis thaliana. Plant Cell Physiol. 37 , 1094-1101. doi: 10.1093/oxfordjournals.pcp.a029059

Gallego-Bartolome, J., Minguet, E. G., Grau-Enguix, F., Abbas, M., Locascio, A., Thomas, S. G., et al. (2012). Molecular mechanism for the interaction between gibberellin and brassinosteroid signaling pathways in Arabidopsis. Proc. Natl. Acad. Sci. U.S.A. 109, 13446-13451. doi: 10.1073/pnas.1119992109

Gazzarrini, S., and Mccourt, P. (2001). Genetic interactions between ABA, ethylene and sugar signaling pathways. Curr. Opin. Plant Biol. 4, 387-391. doi 10.1016/S1369-5266(00)00190-4

Ghassemian, M., Lutes, J., Tepperman, J. M., Chang, H. S., Zhu, T., Wang, X., et al. (2006). Integrative analysis of transcript and metabolite profiling data sets to evaluate the regulation of biochemical pathways during photomorphogenesis. Arch. Biochem. Biophys. 448, 45-59. doi: 10.1016/j.abb.2005.11.020

Gibson, S. I., Laby, R. J., and Kim, D. (2001). The sugar-insensitivel (sis1) mutant of Arabidopsis is allelic to ctr1. Biochem. Biophys. Res. Commun. 280, 196-203. doi: $10.1006 /$ bbrc.2000.4062

Giraudat, J., Hauge, B. M., Valon, C., Smalle, J., Parcy, F., and Goodman, H. M. (1992). Isolation of the Arabidopsis ABI3 gene by positional cloning. Plant Cell 4, 1251-1261. doi: 10.1105/tpc.4.10.1251

Goetz, M., Godt, D. E., and Roitsch, T. (2000). Tissue-specific induction of the mRNA for an extracellular invertase isoenzyme of tomato by brassinosteroids suggests a role for steroid hormones in assimilate partitioning. Plant J. 22, 515-522. doi: 10.1046/j.1365-313x.2000.00766.x

Gomez, L. D., Gilday, A., Feil, R., Lunn, J. E., and Graham, I. A. (2010). AtTPS1-mediated trehalose 6-phosphate synthesis is essential for embryogenic and vegetative growth and responsiveness to ABA in germinating seeds and stomatal guard cells. Plant J. 64, 1-13. doi: 10.1111/j.1365-313X.2010. 04312.x
Greenboim-Wainberg, Y., Maymon, I., Borochov, R., Alvarez, J., Olszewski, N., Ori, N., et al. (2005). Cross talk between gibberellin and cytokinin: the Arabidopsis GA response inhibitor SPINDLY plays a positive role in cytokinin signaling. Plant Cell 17, 92-102. doi: $10.1105 /$ tpc. 104.028472

Guo, H., Yang, H., Mockler, T. C., and Lin, C. (1998). Regulation of flowering time by Arabidopsis photoreceptors. Science 279, 1360-1363. doi: 10.1126/science. 279.5355 .1360

Guzman, P., and Ecker, J. R. (1990). Exploiting the triple response of Arabidopsis to identify ethylene-related mutants. Plant Cell 2, 513-523. doi: 10.1105/tpc.2.6.513

Hanano, S., Domagalska, M. A., Nagy, F., and Davis, S. J. (2006). Multiple phytohormones influence distinct parameters of the plant circadian clock. Genes Cells 11, 1381-1392. doi: 10.1111/j.1365-2443.2006.01026.x

Harberd, N. P., Belfield, E., and Yasumura, Y. (2009). The angiosperm gibberellinGID1-DELLA growth regulatory mechanism: how an "inhibitor of an inhibitor" enables flexible response to fluctuating environments. Plant Cell 21, 1328-1339. doi: $10.1105 /$ tpc. 109.066969

Harmer, S. L. (2009). The circadian system in higher plants. Annu. Rev. Plant Biol. 60, 357-377. doi: 10.1146/annurev.arplant.043008.092054

Haydon, M. J., Mielczarek, O., Robertson, F. C., Hubbard, K. E., and Webb, A. A. (2013). Photosynthetic entrainment of the Arabidopsis thaliana circadian clock. Nature 502, 689-692. doi: 10.1038/nature12603

Hedden, P., and Phillips, A. L. (2000). Manipulation of hormone biosynthetic genes in transgenic plants. Curr. Opin. Biol. 11, 130-137. doi: 10.1016/S09581669(00)00071-9

Huang, Y., Li, C. Y., Biddle, K. D., and Gibson, S. I. (2008). Identification, cloning and characterization of sis7 and sis 10 sugar-insensitive mutants of Arabidopsis. BMC Plant Biol. 8:104. doi: 10.1186/1471-2229-8-104

Huijser, P., and Schmid, M. (2011). The control of developmental phase transitions in plants. Development 138, 4117-4129. doi: 10.1242/dev.063511

Imaizumi, T. (2010). Arabidopsis circadian clock and photoperiodism: time to think about location. Curr. Opin. Plant Biol. 13, 83-89. doi: 10.1016/j.pbi.2009.09.007

Jacobsen, S. E., and Olszewski, N. E. (1993). Mutations at the SPINDLY locus of Arabidopsis alter gibberellin signal transduction. Plant Cell 5, 887-896. doi: 10.1105/tpc.5.8.887

Jeong, J. H., Song, H. R., Ko, J. H., Jeong, Y. M., Kwon, Y. E., Seol, J. H., et al. (2009). Repression of FLOWERING LOCUS T chromatin by functionally redundant histone H3 lysine 4 demethylases in Arabidopsis. PLoS ONE 4:e8033. doi: 10.1371/journal.pone.0008033

Jin, J. B., Jin, Y. H., Lee, J., Miura, K., Yoo, C. Y., Kim, W. Y., et al. (2008). The SUMO E3 ligase, AtSIZ1, regulates flowering by controlling a salicylic acid-mediated floral promotion pathway and through affects on FLC chromatin structure. Plant J. 53, 530-540. doi: 10.1111/j.1365-313X.2007. 03359.x

Jung, J. H., Ju, Y., Seo, P. J., Lee, J. H., and Park, C. M. (2012). The SOC1-SPL module integrates photoperiod and gibberellic acid signals to control flowering time in Arabidopsis. Plant J. 69, 577-588. doi: 10.1111/j.1365-313X.2011. 04813.x

Jung, J. H., Seo, P. J., Kang, S. K., and Park, C. M. (2011). miR172 signals are incorporated into the miR156 signaling pathway at the SPL3/4/5 genes in Arabidopsis developmental transitions. Plant Mol. Biol. 76, 35-45. doi: 10.1007/s11103-0119759-z

Jung, J. H., Seo, Y. H., Seo, P. J., Reyes, J. L., Yun, J., Chua, N. H., et al. (2007) The GIGANTEA-regulated microRNA172 mediates photoperiodic flowering independent of CONSTANS in Arabidopsis. Plant Cell 19, 2736-2748. doi: $10.1105 /$ tpc. 107.054528

Kardailsky, I., Shukla, V. K., Ahn, J. H., Dagenais, N., Christensen, S. K., Nguyen, J. T., et al. (1999). Activation tagging of the floral inducer FT. Science 286 , 1962-1965. doi: 10.1126/science.286.5446.1962

Kieber, J. J., Rothenberg, M., Roman, G., Feldmann, K. A., and Ecker, J. R. (1993). Ctrl, a negative regulator of the ethylene response pathway in Arabidopsis, encodes a member of the Raf family of protein-kinases. Cell 72, 427-441. doi: 10.1016/0092-8674(93)90119-B

Kim, J. J., Lee, J. H., Kim, W., Jung, H. S., Huijser, P., and Ahn, J. H. (2012). The microRNA156-SQUAMOSA PROMOTER BINDING PROTEINLIKE3 module regulates ambient temperature-responsive flowering via FLOWERING LOCUS T in Arabidopsis. Plant Physiol. 159, 461-478. doi: $10.1104 /$ pp.111.192369 
Kleine, T., Lockhart, P., and Batschauer, A. (2003). An Arabidopsis protein closely related to Synechocystis cryptochrome is targeted to organelles. Plant J. 35, 93-103. doi: 10.1046/j.1365-313X.2003.01787.x

Kobayashi, Y., Kaya, H., Goto, K., Iwabuchi, M., and Araki, T. (1999). A pair of related genes with antagonistic roles in mediating flowering signals. Science 286 , 1960-1962. doi: 10.1126/science.286.5446.1960

Koornneef, M., and Van Der Veen, J. H. (1980). Induction and analysis of gibberellin sensitive mutants in Arabidopsis thaliana (L.) heynh. Theor. Appl. Genet. 58, 257-263. doi: 10.1007/BF00265176

Kreps, J. A., and Simon, A. E. (1997). Environmental and genetic effects on circadian clock-regulated gene expression in Arabidopsis. Plant Cell 9, 297-304. doi: 10.1105/tpc.9.3.297

Kurup, S., Jones, H. D., and Holdsworth, M. J. (2000). Interactions of the developmental regulator ABI3 with proteins identified from developing Arabidopsis seeds. Plant J. 21, 143-155. doi: 10.1046/j.1365-313x.2000. 00663.x

Laby, R. J., Kincaid, M. S., Kim, D. G., and Gibson, S. I. (2000). The Arabidopsis sugar-insensitive mutants sis 4 and sis 5 are defective in abscisic acid synthesis and response. Plant J. 23, 587-596. doi: 10.1046/j.1365-313x.2000. 00833.x

Lalonde, S., Boles, E., Hellmann, H., Barker, L., Patrick, J. W., Frommer, W. B., et al. (1999). The dual function of sugar carriers. Transport and sugar sensing. Plant Cell 11, 707-726. doi: 10.1105/tpc.11.4.707

Laxmi, A., Paul, L. K., Peters, J. L., and Khurana, J. P. (2004). Arabidopsis constitutive photomorphogenic mutant, bls1, displays altered brassinosteroid response and sugar sensitivity. Plant Mol. Biol. 56, 185-201. doi: 10.1007/s11103-0042799-x

Lee, J., Oh, M., Park, H., and Lee, I. (2008). SOC1 translocated to the nucleus by interaction with AGL24 directly regulates LEAFY. Plant J. 55, 832-843. doi: 10.1111/j.1365-313X.2008.03552.x

Leon, P., and Sheen, J. (2003). Sugar and hormone connections. Trends Plant Sci. 8 , 110-116. doi: 10.1016/S1360-1385(03)00011-6

Leon-Kloosterziel, K. M., Gil, M. A., Ruijs, G. J., Jacobsen, S. E., Olszewski, N. E., Schwartz, S. H., et al. (1996). Isolation and characterization of abscisic acid-deficient Arabidopsis mutants at two new loci. Plant J. 10, 655-661. doi: 10.1046/j.1365-313X.1996.10040655.x

Li, J., Nagpal, P., Vitart, V., Mcmorris, T. C., and Chory, J. (1996). A role for brassinosteroids in light-dependent development of Arabidopsis. Science 272, 398-401. doi: 10.1126/science.272.5260.398

Li, J. M., and Chory, J. (1997). A putative leucine-rich repeat receptor kinase involved in brassinosteroid signal transduction. Cell 90, 929-938. doi 10.1016/S0092-8674(00)80357-8

Li, J. M., Nam, K. H., Vafeados, D., and Chory, J. (2001). BIN2, a new brassinosteroid-insensitive locus in Arabidopsis. Plant Physiol. 127, 14-22. doi: 10.1104/pp.127.1.14

Li, P., Wind, J. J., Shi, X., Zhang, H., Hanson, J., Smeekens, S. C., et al. (2011). Fructose sensitivity is suppressed in Arabidopsis by the transcription factor ANAC089 lacking the membrane-bound domain. Proc. Natl. Acad. Sci. U.S.A. 108, 3436-3441. doi: 10.1073/pnas. 1018665108

Liu, C., Chen, H., Er, H. L., Soo, H. M., Kumar, P. P., Han, J. H., et al. (2008). Direct interaction of AGL24 and SOC1 integrates flowering signals in Arabidopsis. Development 135, 1481-1491. doi: 10.1242/dev.020255

Lloyd, J. C., and Zakhleniuk, O. V. (2004). Responses of primary and secondary metabolism to sugar accumulation revealed by microarray expression analysis of the Arabidopsis mutant, pho3. J. Exp. Bot. 55, 1221-1230. doi: $10.1093 /$ jxb/erh 143

Lunn, J. E., Feil, R., Hendriks, J. H., Gibon, Y., Morcuende, R., Osuna, D., et al. (2006). Sugar-induced increases in trehalose 6-phosphate are correlated with redox activation of ADPglucose pyrophosphorylase and higher rates of starch synthesis in Arabidopsis thaliana. Biochem. J. 397, 139-148. doi: 10.1042/BJ20060083

Martinez-Zapater, J. M., Coupland, G., Dean, C., and Koornneef, M. (1994). "The transition to flowering in Arabidopsis," in Arabidopsis, eds E. M. Meyerowitz and C. R. Somerville (Cold Spring Harbor, NY: Cold Spring Harbor Laboratory Press), 403-433.

Martins, M. C., Hejazi, M., Fettke, J., Steup, M., Feil, R., Krause, U., et al. (2013). Feedback inhibition of starch degradation in Arabidopsis leaves mediated by trehalose 6-phosphate. Plant Physiol. 163, 1142-1163. doi: $10.1104 /$ pp.113.226787
Mathieu, J., Yant, L. J., Murdter, F., Kuttner, F., and Schmid, M. (2009). Repression of flowering by the miR172 target SMZ. PLoS Biol. 7:e1000148. doi: 10.1371/journal.pbio.1000148

Matsoukas, I. G. (2014). Attainment of reproductive competence, phase transition, and quantification of juvenility in mutant genetic screens. Front. Plant Sci. 5:32. doi: $10.3389 /$ fpls.2014.00032

Matsoukas, I. G., Massiah, A. J., and Thomas, B. (2012). Florigenic and antiflorigenic signalling in plants. Plant Cell Physiol. 53, 1827-1842. doi: $10.1093 / \mathrm{pcp} / \mathrm{pcs} 130$

Matsoukas, I. G., Massiah, A. J., and Thomas, B. (2013). Starch metabolism and antiflorigenic signals modulate the juvenile-to-adult phase transition in Arabidopsis. Plant Cell Environ. 36, 1802-1811. doi: 10.1111/pce.12088

Melzer, S., Lens, F., Gennen, J., Vanneste, S., Rohde, A., and Beeckman, T. (2008). Flowering-time genes modulate meristem determinacy and growth form in Arabidopsis thaliana. Nat. Genet. 40, 1489-1492. doi: 10.1038/ng.253

Michaels, S. D. (2009). Flowering time regulation produces much fruit. Curr. Opin Plant Biol. 12, 75-80. doi: 10.1016/j.pbi.2008.09.005

Mizoguchi, T., Wheatley, K., Hanzawa, Y., Wright, L., Mizoguchi, M., Song, H. R., et al. (2002). LHY and CCA1 are partially redundant genes required to maintain circadian rhythms in Arabidopsis. Dev. Cell 2, 629-641. doi: 10.1016/S15345807(02)00170-3

Moore, B., Zhou, L., Rolland, F., Hall, Q., Cheng, W. H., Liu, Y. X., et al. (2003). Role of the Arabidopsis glucose sensor HXK1 in nutrient, light, and hormonal signaling. Science 300, 332-336. doi: 10.1126/science. 1080585

Neff, M. M., Nguyen, S. M., Malancharuvil, E. J., Fujioka, S., Noguchi, T., Seto, H., et al. (1999). BAS1: a gene regulating brassinosteroid levels and light responsiveness in Arabidopsis. Proc. Natl. Acad. Sci. U.S.A. 96, 15316-15323. doi: 10.1073/pnas.96.26.15316

Niittyla, T., Messerli, G., Trevisan, M., Chen, J., Smith, A. M., and Zeeman, S. C. (2004). A previously unknown maltose transporter essential for starch degradation in leaves. Science 303, 87-89. doi: 10.1126/science.1091811

Niu, X., Helentjaris, T., and Bate, N. J. (2002). Maize ABI4 binds coupling element1 in abscisic acid and sugar response genes. Plant Cell 14, 2565-2575. doi: $10.1105 /$ tpc. 003400

Noguchi, T., Fujioka, S., Takatsuto, S., Sakurai, A., Yoshida, S., Li, J., et al. (1999). Arabidopsis det2 is defective in the conversion of (24R)-24-methylcholest-4-En3-one to (24R)-24-methyl-5alpha-cholestan-3-one in brassinosteroid biosynthesis. Plant Physiol. 120, 833-840. doi: 10.1104/pp.120.3.833

Nozue, K., Harmer, S. L., and Maloof, J. N. (2011). Genomic analysis of circadian clock-, light-, and growth-correlated genes reveals PHYTOCHROMEINTERACTING FACTOR5 as a modulator of auxin signaling in Arabidopsis. Plant Physiol. 156, 357-372. doi: 10.1104/pp.111.172684

Oh, E., Zhu, J. Y., and Wang, Z. Y. (2012). Interaction between BZR1 and PIF4 integrates brassinosteroid and environmental responses. Nat. Cell Biol. 14, 802-809. doi: $10.1038 /$ ncb2545

Ohto, M., Onai, K., Furukawa, Y., Aoki, E., Araki, T., and Nakamura, K. (2001). Effects of sugar on vegetative development and floral transition in arabidopsis. Plant Physiol. 127, 252-261. doi: 10.1104/pp.127.1.252

Paparelli, E., Parlanti, S., Gonzali, S., Novi, G., Mariotti, L., Ceccarelli, N., et al. (2013). Nighttime sugar starvation orchestrates gibberellin biosynthesis and plant growth in Arabidopsis. Plant Cell 25, 3760-3769. doi: 10.1105/tpc.113.115519

Penfield, S., and Hall, A. (2009). A role for multiple circadian clock genes in the response to signals that break seed dormancy in Arabidopsis. Plant Cell 21, 1722-1732. doi: $10.1105 /$ tpc. 108.064022

Peng, J., Carol, P., Richards, D. E., King, K. E., Cowling, R. J., Murphy, G. P., et al. (1997). The Arabidopsis GAI gene defines a signaling pathway that negatively regulates gibberellin responses. Genes Dev. 11, 3194-3205. doi: 10.1101/gad.11.23.3194

Peng, J., and Harberd, N. P. (1993). Derivative alleles of the Arabidopsis gibberellininsensitive (gai) mutation confer a wild-type phenotype. Plant Cell 5, 351-360. doi: $10.1105 /$ tpc.5.3.351

Poethig, R. S. (1990). Phase change and the regulation of shoot morphogenesis in plants. Science 250, 923-930. doi: 10.1126/science.250.4983.923

Poethig, R. S. (2013). Vegetative phase change and shoot maturation in plants. Curr. Top. Dev. Biol. 105, 125-152. doi: 10.1016/B978-0-12-396968-2.00005-1

Pokhilko, A., Mas, P., and Millar, A. J. (2013). Modelling the widespread effects of TOC1 signalling on the plant circadian clock and its outputs. BMC Syst. Biol. 7:23. doi: $10.1186 / 1752-0509-7-23$ 
Polge, C., and Thomas, M. (2007). SNF1/AMPK/SnRK1 kinases, global regulators at the heart of energy control? Trends Plant Sci. 12, 20-28. doi: 10.1016/j.tplants.2006.11.005

Ponnu, J., Wahl, V., and Schmid, M. (2011). Trehalose-6-phosphate: connecting plant metabolism and development. Front. Plant Sci. 2:70. doi: $10.3389 /$ fpls.2011.00070

Porri, A., Torti, S., Romera-Branchat, M., and Coupland, G. (2012). Spatially distinct regulatory roles for gibberellins in the promotion of flowering of Arabidopsis under long photoperiods. Development 139, 2198-2209. doi: 10.1242/dev.077164

Price, J., Laxmi, A., St Martin, S. K., and Jang, J. C. (2004). Global transcription profiling reveals multiple sugar signal transduction mechanisms in Arabidopsis. Plant Cell 16, 2128-2150. doi: 10.1105/tpc.104.022616

Quiroz-Figueroa, F., Rodriguez-Acosta, A., Salazar-Blas, A., HernandezDominguez, E., Campos, M. E., Kitahata, N., et al. (2010). Accumulation of high levels of ABA regulates the pleiotropic response of the nhr1 Arabidopsis mutant. J. Plant Biol. 53, 32-44. doi: 10.1007/s12374-0099083-1

Rolland, F., Baena-Gonzalez, E., and Sheen, J. (2006). Sugar sensing and signaling in plants: conserved and novel mechanisms. Annu. Rev. Plant Biol. 57, 675-709. doi: 10.1146/annurev.arplant.57.032905.105441

Roman, G., Lubarsky, B., Kieber, J. J., Rothenberg, M., and Ecker, J. R. (1995). Genetic analysis of ethylene signal transduction in Arabidopsis thaliana: five novel mutant loci integrated into a stress response pathway. Genetics 139, 1393-1409.

Rook, F., Corke, F., Card, R., Munz, G., Smith, C., and Bevan, M. W. (2001). Impaired sucrose-induction mutants reveal the modulation of sugar-induced starch biosynthetic gene expression by abscisic acid signalling. Plant J. 26, 421-433. doi: 10.1046/j.1365-313X.2001.2641043.x

Sakai, H., Hua, J., Chen, Q. G., Chang, C., Medrano, L. J., Bleecker, A. B., et al. (1998). ETR2 is an ETR1-like gene involved in ethylene signaling in Arabidopsis. Proc. Natl. Acad. Sci. U.S.A. 95, 5812-5817. doi: 10.1073/pnas.95. 10.5812

Schaffer, R., Ramsay, N., Samach, A., Corden, S., Putterill, J., Carre, I. A., et al. (1998). The late elongated hypocotyl mutation of Arabidopsis disrupts circadian rhythms and the photoperiodic control of flowering. Cell 93, 1219-1229. doi: 10.1016/S0092-8674(00)81465-8

Schluter, U., Kopke, D., Altmann, T., and Mussig, C. (2002). Analysis of carbohydrate metabolism of $\mathrm{CPD}$ antisense plants and the brassinosteroiddeficient cbb1 mutant. Plant Cell Environ. 25, 783-791. doi: 10.1046/j.13653040.2002.00860.x

Schmitz, R. J., Sung, S., and Amasino, R. M. (2008). Histone arginine methylation is required for vernalization-induced epigenetic silencing of FLC in winterannual Arabidopsis thaliana. Proc. Natl. Acad. Sci. U.S.A. 105, 411-416. doi: 10.1073/pnas.0710423104

Schwab, R., Palatnik, J. F., Riester, M., Schommer, C., Schmid, M., and Weigel, D. (2005). Specific effects of microRNAs on the plant transcriptome. Dev. Cell. 8 517-527. doi: 10.1016/j.devcel.2005.01.018

Schwarz, S., Grande, A. V., Bujdoso, N., Saedler, H., and Huijser, P. (2008). The microRNA regulated SBP-box genes SPL9 and SPL15 control shoot maturation in Arabidopsis. Plant Mol. Biol. 67, 183-195. doi: 10.1007/s11103-0089310-z

Seo, P. J., Ryu, J., Kang, S. K., and Park, C. M. (2011). Modulation of sugar metabolism by an INDETERMINATE DOMAIN transcription factor contributes to photoperiodic flowering in Arabidopsis. Plant J. 65, 418-429. doi: 10.1111/j.1365-313X.2010.04432.x

Sgamma, T., Jackson, A., Muleo, R., Thomas, B., and Massiah, A. (2014). TEMPRANILLO is a regulator of juvenility in plants. Sci. Rep. 4:3704. doi: 10.1038/srep03704

Sharrock, R. A., and Quail, P. H. (1989). Novel phytochrome sequences in Arabidopsis thaliana: structure, evolution, and differential expression of a plant regulatory photoreceptor family. Genes Dev. 3, 1745-1757. doi: 10.1101/gad.3.11.1745

Smeekens, S., Ma, J., Hanson, J., and Rolland, F. (2010). Sugar signals and molecular networks controlling plant growth. Curr. Opin. Plant Biol. 13, 274-279. doi: 10.1016/j.pbi.2009.12.002

Somers, D. E., Webb, A. A., Pearson, M., and Kay, S. A. (1998). The short-period mutant, toc1-1, alters circadian clock regulation of multiple outputs throughout development in Arabidopsis thaliana. Development 125, 485-494.
Stettler, M., Eicke, S., Mettler, T., Messerli, G., Hortensteiner, S., and Zeeman, S. C. (2009). Blocking the metabolism of starch breakdown products in Arabidopsis leaves triggers chloroplast degradation. Mol. Plant 2, 1233-1246. doi: $10.1093 / \mathrm{mp} / \mathrm{ssp} 093$

Stewart, J. L., Maloof, J. N., and Nemhauser, J. L. (2011). PIF genes mediate the effect of sucrose on seedling growth dynamics. PLoS ONE 6:e19894. doi: 10.1371/journal.pone.0019894

Stitt, M., and Zeeman, S. C. (2012). Starch turnover: pathways, regulation and role in growth. Curr. Opin. Plant Biol. 15, 282-292. doi: 10.1016/j.pbi.2012.03.016

Su, W., and Howell, S. H. (1992). A single genetic locus, ckrl, defines Arabidopsis mutants in which root growth is resistant to low concentrations of cytokinin. Plant Physiol. 99, 1569-1574. doi: 10.1104/pp.99.4.1569

Swain, S. M., Tseng, T. S., Thornton, T. M., Gopalraj, M., and Olszewski, N. E. (2002). SPINDLY is a nuclear-localized repressor of gibberellin signal transduction expressed throughout the plant. Plant Physiol. 129, 605-615. doi: $10.1104 /$ pp. 020002

Szekeres, M., Nemeth, K., Konczkalman, Z., Mathur, J., Kauschmann, A., Altmann, T., et al. (1996). Brassinosteroids rescue the deficiency of CYP90, a cytochrome P450, controlling cell elongation and de-etiolation in arabidopsis. Cell 85, 171-182. doi: 10.1016/S0092-8674(00)81094-6

Tanaka, K., Asami, T., Yoshida, S., Nakamura, Y., Matsuo, T., and Okamoto, S. (2005). Brassinosteroid homeostasis in Arabidopsis is ensured by feedback expressions of multiple genes involved in its metabolism. Plant Physiol. 138, 1117-1125. doi: 10.1104/pp.104.058040

Tseng, T. S., Salome, P. A., Mcclung, C. R., and Olszewski, N. E. (2004). SPINDLY and GIGANTEA interact and act in Arabidopsis thaliana pathways involved in light responses, flowering, and rhythms in cotyledon movements. Plant Cell 16, 1550-1563. doi: 10.1105/tpc.019224

Turck, F., Fornara, F., and Coupland, G. (2008). Regulation and identity of florigen: FLOWERING LOCUS T moves center stage. Annu. Rev. Plant Biol. 59, 573-594. doi: 10.1146/annurev.arplant.59.032607.092755

Turk, E. M., Fujioka, S., Seto, H., Shimada, Y., Takatsuto, S., Yoshida, S., et al. (2005). BAS1 and SOB7 act redundantly to modulate Arabidopsis photomorphogenesis via unique brassinosteroid inactivation mechanisms. Plant J. 42, 23-34. doi: 10.1111/j.1365-313X.2005.02358.x

Tyler, L., Thomas, S. G., Hu, J., Dill, A., Alonso, J. M., Ecker, J. R., et al. (2004). Della proteins and gibberellin-regulated seed germination and floral development in Arabidopsis. Plant Physiol. 135, 1008-1019. doi: 10.1104/pp.104.039578

Van Dijken, A. J., Schluepmann, H., and Smeekens, S. C. (2004). Arabidopsis trehalose-6-phosphate synthase 1 is essential for normal vegetative growth and transition to flowering. Plant Physiol. 135, 969-977. doi: 10.1104/pp.104.039743

Wahl, V., Ponnu, J., Schlereth, A., Arrivault, S., Langenecker, T., Franke, A. et al. (2013). Regulation of flowering by trehalose-6-phosphate signaling in Arabidopsis thaliana. Science 339, 704-707. doi: 10.1126/science.1230406

Wang, J. W., Czech, B., and Weigel, D. (2009). miR156-regulated SPL transcription factors define an endogenous flowering pathway in Arabidopsis thaliana. Cell 138, 738-749. doi: 10.1016/j.cell.2009.06.014

Wang, Y., Li, L., Ye, T., Lu, Y., Chen, X., and Wu, Y. (2013). The inhibitory effect of ABA on floral transition is mediated by ABI5 in Arabidopsis. J. Exp. Bot. 64 675-684. doi: 10.1093/jxb/ers361

Wang, Z. Y., Kenigsbuch, D., Sun, L., Harel, E., Ong, M. S., and Tobin, E. M. (1997). A Myb-related transcription factor is involved in the phytochrome regulation of an Arabidopsis Lhcb gene. Plant Cell 9, 491-507. doi: 10.1105/tpc.9.4.491

Wigge, P. A., Kim, M. C., Jaeger, K. E., Busch, W., Schmid, M., Lohmann, J. U., et al. (2005). Integration of spatial and temporal information during floral induction in Arabidopsis. Science 309, 1056-1059. doi: 10.1126/science.1114358

Wu, G., Park, M. Y., Conway, S. R., Wang, J. W., Weigel, D., and Poethig, R. S. (2009). The sequential action of miR156 and miR172 regulates developmental timing in Arabidopsis. Cell 138, 750-759. doi: 10.1016/j.cell.2009. 06.031

Wuriyanghan, H., Zhang, B., Cao, W. H., Ma, B., Lei, G., Liu, Y. F., et al. (2009). The ethylene receptor ETR2 delays floral transition and affects starch accumulation in rice. Plant Cell 21, 1473-1494. doi: 10.1105/tpc.108. 065391

Yamaguchi, A., Kobayashi, Y., Goto, K., Abe, M., and Araki, T. (2005). Twin Sister of FT (TSF) acts as a floral pathway integrator redundantly with FT. Plant Cell Physiol. 46, 1175-1189. doi: 10.1093/pcp/pci151

Yamaguchi, A., Wu, M. F., Yang, L., Wu, G., Poethig, R. S., and Wagner, D. (2009). The microRNA-regulated SBP-Box transcription factor SPL3 is a direct 
upstream activator of LEAFY, FRUITFULL, and APETALA1. Dev. Cell. 17, 268-278. doi: 10.1016/j.devcel.2009.06.007

Yamaguchi-Shinozaki, K., and Shinozaki, K. (2005). Organization of cis-acting regulatory elements in osmotic- and cold-stress-responsive promoters. Trends Plant Sci. 10, 88-94. doi: 10.1016/j.tplants.2004.12.012

Yanagisawa, S., Yoo, S. D., and Sheen, J. (2003). Differential regulation of EIN3 stability by glucose and ethylene signalling in plants. Nature $425,521-525$. doi: 10.1038/nature01984

Yang, L., Conway, S. R., and Poethig, R. S. (2011). Vegetative phase change is mediated by a leaf-derived signal that represses the transcription of miR156. Development 138, 245-249. doi: 10.1242/dev. 058578

Yang, L., Xu, M., Koo, Y., He, J., and Poethig, R. S. (2013). Sugar promotes vegetative phase change in Arabidopsis thaliana by repressing the expression of MIR156A and MIR156C. eLife 2:e00260. doi: 10.7554/eLife. 00260

Yoo, S. K., Chung, K. S., Kim, J., Lee, J. H., Hong, S. M., Yoo, S. J., et al. (2005). CONSTANS activates SUPPRESSOR OFOVEREXPRESSION OFCONSTANS through FLOWERING LOCUS T to promote flowering in Arabidopsis. Plant Physiol. 139, 770-778. doi: 10.1104/pp.105.066928

Yu, H., Ito, T., Zhao, Y., Peng, J., Kumar, P., and Meyerowitz, E. M. (2004). Floral homeotic genes are targets of gibberellin signaling in flower development. Proc. Natl. Acad. Sci. U.S.A. 101, 7827-7832. doi: 10.1073/pnas.04023 77101

Yu, S., Cao, L., Zhou, C.-M., Zhang, T.-Q., Lian, H., Sun, Y., et al. (2013). Sugar is an endogenous cue for juvenile-to-adult phase transition in plants. eLife 2:e00269. doi: 10.7554/eLife.00269

Yu, S., Galvao, V. C., Zhang, Y. C., Horrer, D., Zhang, T. Q., Hao, Y. H., et al. (2012). Gibberellin regulates the Arabidopsis floral transition through miR156targeted SQUAMOSA promoter binding-like transcription factors. Plant Cell 24, 3320-3332. doi: 10.1105/tpc.112.101014
Yuan, K., and Wysocka-Diller, J. (2006). Phytohormone signalling pathways interact with sugars during seed germination and seedling development. J. Exp. Bot. 57, 3359-3367. doi: 10.1093/jxb/erl096

Zakhleniuk, O. V., Raines, C. A., and Lloyd, J. C. (2001). pho3: a phosphorusdeficient mutant of Arabidopsis thaliana (L.) Heynh. Planta 212, 529-534. doi: $10.1007 / \mathrm{s} 004250000450$

Zhang, Y., Primavesi, L. F., Jhurreea, D., Andralojc, P. J., Mitchell, R. A., Powers, S. J., et al. (2009). Inhibition of SNF1-related protein kinase1 activity and regulation of metabolic pathways by trehalose-6-phosphate. Plant Physiol. 149, 1860-1871. doi: 10.1104/pp.108.133934

Zhou, L., Jang, J. C., Jones, T. L., and Sheen, J. (1998). Glucose and ethylene signal transduction crosstalk revealed by an Arabidopsis glucose-insensitive mutant. Proc. Natl. Acad. Sci. U.S.A. 95, 10294-10299. doi: 10.1073/pnas.95.17.10294

Conflict of Interest Statement: The author declares that the research was conducted in the absence of any commercial or financial relationships that could be construed as a potential conflict of interest.

Received: 18 March 2014; paper pending published: 19 May 2014; accepted: 24 June 2014; published online: 13 August 2014.

Citation: Matsoukas IG (2014) Interplay between sugar and hormone signaling pathways modulate floral signal transduction. Front. Genet. 5:218. doi: 10.3389/fgene. 2014.00218

This article was submitted to Plant Genetics and Genomics, a section of the journal Frontiers in Genetics.

Copyright (c) 2014 Matsoukas. This is an open-access article distributed under the terms of the Creative Commons Attribution License (CC BY). The use, distribution or reproduction in other forums is permitted, provided the original author(s) or licensor are credited and that the original publication in this journal is cited, in accordance with accepted academic practice. No use, distribution or reproduction is permitted which does not comply with these terms. 